\title{
Numerical Simulation Analysis of Water Injection Seepage Law in Micro Porous Structure of Coal
}

\author{
Gang ZHOU, Lei QIU, Wen-Zheng ZHANG, Jiao XUE, Ming-Guang ZHANG
}

\begin{abstract}
In this paper, a nano Voxel X-ray 3D microscope is used to scan the long flame coal samples and to reconstruct the 3D pore structure by the use of microscopic computed tomography. With image segmentation technique, a model of micro-pore structure of coal is obtained from the reconstructed coal. With different planes selected as seepage inlets, a numerical simulation of low-pressure water seepage is conducted. Studies show that water pressure gradually decreases along the direction of water seepage and reaches the maximum at the pore-pipes with good connectivity near the inlet. Due to the difference between the structure and development direction of pores in the three dimensions, there is an optimal seepage outlet that is most appropriately corresponding to each seepage inlet. When different planes are selected as seepage inlets, the velocity of each seepage outlet is positively correlated with the seepage mass flow rate at the outlet.
\end{abstract}

Keywords: micro CT; micro-pore structure of coal; rule of seepage; visualization

\section{INTRODUCTION}

Coal seam is a porous medium, the micro-pore structure influences many physical properties of coal, including its porosity, permeability, density, water absorption, softening and weakening performance of water injection. Therefore, the structure determines, to a great extent, the occurrence and flow characteristics of gas and liquid in coal seam. As a result, the study on micro-pore structure of coal is significant to the drainage of gas from coal seam, water injection in coal seam and spontaneous combustion of coal [1-4].

Micro CT is one of today's most popular and fastestgrowing types of computed tomography technology, and it is widely applied to the fields of micro and nano manufacturing, new materials and electronic science. In comparison with macrostructure CT for medical detection, micro CT has high resolution (as high as 0,5 1 $1 \mu \mathrm{m}$ ) that enables measurement and analysis of the microstructure of small-sized materials and products [5-10].

In recent years, more and more researchers have used computed tomography to study the microstructure of coal and flow characteristics within it. Nie et al. and Wang et al. observed the microstructure of fractures inside coal using CT scanning [11, 12]. Cheng et al. and Li et al. used a quantitative method to characterize the development of pores, and the fractures of different coal types and their spatial distribution $[13,14]$.Song et al. and Ma et al. made an elaborate and quantitative characterization of the seepage pores of coal taken from the Southern Zhongliangshan Coal Mine in Chongqing by micro CT [15-19]. Li et al. and Mostaghimi et al. built a 3D model of coal pores of different structures and made a quantitative evaluation on the change of connectivity and permeability of large-sized pores $(d>1 \mu \mathrm{m})$ by CT and 3D percolation theory [20, 21]. Mayo et al. and Simons et al. made quantitative coal characterization with a precision of about $53 \mu \mathrm{m}$ by the use of CT reconstruction technique [22, 23]. Mazumder et al. analyzed the cleat and aperture spacing using CT $[24,25]$. The distribution of minerals, macerals and pores and fractures of coal was obtained by Golab et al. and Van Geet et al. through micro-focal X-CT experiments $[26,27]$. The thermal drying process of sub- bituminous coal was observed by Mathews et al. who used high-resolution CT [28]. Karacan and Okandan investigated and evaluated the adsorption and migration of gas in the microstructure of coal by the use of CT imaging [29]. However, the insufficient precision of equipment used in above studies results in large deviations of the analysis results from the real structure, and decouples the structure and seepage studies of coal.

In addition, there are very few reports on the highprecision micro-pore structure of coal to investigate the rules of seepage during water injection. Zhou et al. [30, 31] take long flame coal as an example, using CT technology to characterize the real pore in coal, and a low-pressure water seepage simulation was carried out. The variation rule of water pressure and velocity in seepage process was analyzed. However, only one direction of water injection seepage state is analyzed in this study, and the flow direction of water is no single in the process of actual coal seam flooding. Therefore, by choosing different surface seepage was simulated as imported one in five out of the water flow, analysis of pressure field and velocity field distribution. Based on the simulation, quantitative calculation was performed for the distribution pattern of mass flow rate and velocity of the inlet and outlet planes.

\section{FUNDAMENTAL OF MICRO CT}

An X-ray 3D microscopic imaging system mainly consists of a micro-focal X-ray source, a precise sample stage, a high-resolution detector, a control system, and an imaging and analyzing software. The scanning process is as the following: the micro-focal X-ray source and the high-resolution detector are kept still; the precise sample stage is rotated to get transmission images from different views; one circular scan at every $360^{\circ}$ rotation is completed to obtain a series of transmission images.

When X-rays interact with the object, different compositions absorb different quantities of X-ray photons. The quantity is determined by the energy of X-rays, $E$, the density of the object, $\rho$, and the atomic number, $Z$. $I_{0}$ is the intensity of X-rays. $L$ is the route of X-rays passing through the object. $I_{\mathrm{d}}(L)$ is the intensity of X-rays detected by the detector and can be expressed as: 


$$
I_{\mathrm{d}}(L)=I_{0} \mathrm{e}^{-\int \mu(x, E) \mathrm{d} L}
$$

where $\mu$ is the adsorption coefficient of X-rays, $x$ is the spatial location. For simple materials, the adsorption coefficient can be expressed as:

$$
\mu(E)=\rho\left(a+b \frac{z^{3.8}}{E^{3.2}}\right)
$$

where $a$ is a parameter of weak energy dependence and $b$ is a constant [32].

\section{CT MODELING OF MICRO-PORE STRUCTURE OF COAL USING MICRO CT}

3.1 Equipment Description

The nanoVoxel series X-ray 3D microscope (micro CT) used in this study has a high-resolution of detection for non-destructive imaging of the 3D internal structure of samples. The equipment is capable of three-dimensional characterization and digital reconstruction of the internal microstructure of samples in submicron dimension and for reverse engineering analysis. Fig. 1 shows a photo of a NanoVoxel-2000 series X-ray 3D microscope. The X-ray $3 \mathrm{D}$ micro imaging system has various scanning modes, including columnar scan, spiral scan, offset scan, finite angle scan and hyper-view scan, and it meets the demands for testing samples of different sizes.

\subsection{Scanning Process}

A small coal column with a diameter of $1,2 \mathrm{~mm}$ is bored from a long flame coal sample in the Daliuta Coal Mine, ground evenly and then sealed with wax. The diameter of the sealed coal column is $1,51 \mathrm{~mm}$ as shown in Fig. 2.

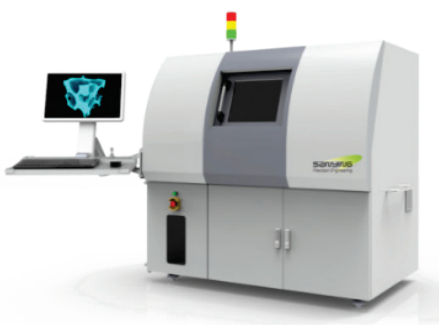

Figure 1 NanoVoxel-2000 series X-ray 3D microscope of coal sample

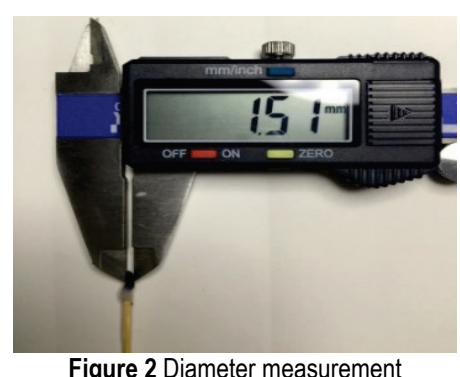

Figure 2 Diameter measurement

The sealed coal column is secured on a toothpick and placed on the sample stage of the X-ray 3D microscope. During the rotating process, the sample should be secured still to ensure the accuracy of reconstruction after the completion of scan. The hyper-view scan mode is used to scan the coal column. Tab. 1 shows the specific scanning parameters. A $20 \mathrm{X}$ lens is selected for the detector. The source-to-detector distance (SOD) is $35 \mathrm{~mm}$ and the objectto-detector distance (ODD) is $13 \mathrm{~mm}$. Upon the completion of scanning, a $1024 \times 1024 \times 1008$ dimension is obtained for the coal, and it stands for the actual dimension of 1,024 $\mathrm{mm} \times 1,024 \mathrm{~mm} \times 1,008 \mathrm{~mm}$. This $3 \mathrm{D}$ data is then saved in RAW format and exported

\begin{tabular}{|c|c|c|c|c|c|c|c|}
\hline $\begin{array}{l}\text { Type of } \\
\text { detector }\end{array}$ & $\mathrm{SOD} / \mathrm{ODD} / \mathrm{mm} / \mathrm{mm}$ & Voltage / kV & Current $/ \mu \mathrm{A}$ & $\begin{array}{l}\text { Scan } \\
\text { frame }\end{array}$ & Duration / h & $\begin{array}{c}\text { Exposure time } \\
\text { / s }\end{array}$ & $\begin{array}{c}\text { Penetration rate } \\
/ \%\end{array}$ \\
\hline $20 X$ & $35 / 13$ & 41 & 240 & 900 & 19 & 65 & 53 \\
\hline
\end{tabular}

Table 1 Setting of the scanning parameters of X-ray 3D microscope

\subsection{Modeling of Micro-Pore Structure of Coal}

AvizoTM software is a versatile visualization tool. The RAW data obtained after scan and reconstruction by the Xray $3 \mathrm{D}$ microscope are imported to Avizo. The configuration is 16-bit unsigned as Data type, $1024 \times 1024$ $\times 1008$ in dimensions, and $1 \mu \mathrm{m} \times 1 \mu \mathrm{m} \times 1 \mu \mathrm{m}$ in voxel size. The Volume Rendering function visualizes the microstructure of coal in 3D, as shown in Fig. 3. A target box is generated by clicking Extract Subvolume.

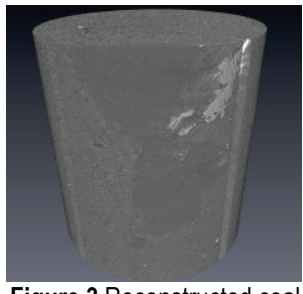

Figure 3 Reconstructed coal

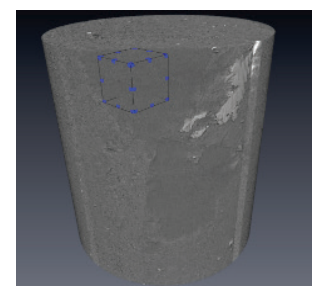

Figure 4 Target box

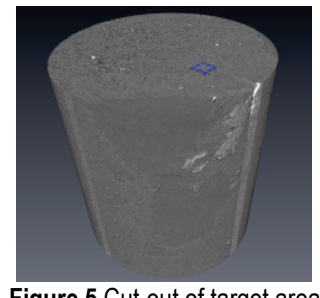

Figure 5 Cut-out of target area

By changing the size and position of the target box, the target area of the study is determined as 60 pix $\times 60$ pix $\times$ 60 pix, as shown in Fig. 4 and Fig. 5. This means that the real three dimensions of the coal in the selected target area 
are $60 \mu \mathrm{m} \times 60 \mu \mathrm{m} \times 60 \mu \mathrm{m}$ since the resolution of the original micro CT equipment is $1 \mu \mathrm{m} /$ pix.

At this point, the structure of the target coal can be $3 \mathrm{D}$ visualized via the volume rendering function as shown in Fig. 6. Then, the image segmentation technique is used to obtain a model of a micro-pore structure as shown in Fig. 7, where the purple color indicates the pore structure of coal. The remainder refers to coal which, if concealed, enables the visualization of the micro-pore structure of coal as shown in Fig. 8. This study selects the micro-model developed based on the coal's real pore structure as the geometric model in seepagesimulation. Compared with other models established by other scholars based on CT two-dimensional (2D) slices, the established model in this study is more in line with the actual seepage state [33].

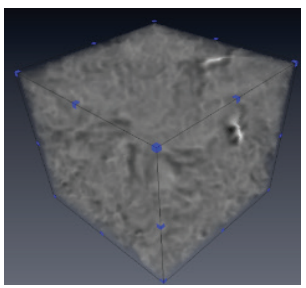

Figure 6 Target coal

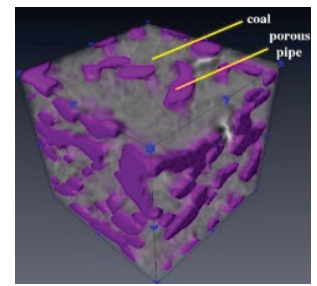

Figure 7 Diagram of coal and pore structure distribution

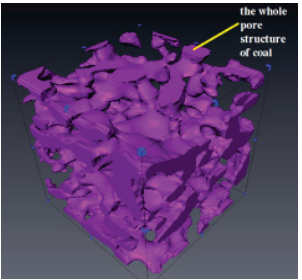

Figure 8 Model of micro-pore structure of coal

\section{SIMULATION OF SEEPAGE DURING WATER INJECTION AND RESULT ANALYSIS}

This paper uses a CFX15.0 software to numerically study the rules of seepage during water injection in the micro-pore structure of coal, which is unlike the simulations on fluid's seepage behaviors by Bird et al. via the combination of Avizo and COMSOL, which can help to effectively observe and analyze the calculation results of fluid flow.

\subsection{Meshing of Micro Pore Model and Setting of Simulation Conditions}

A coal pore structure model is imported from STL file into ICEM CFD software. Then, the model is split for isolated pores (isolated pore is a pore structure that individually exists and is disconnected from the biggest pore connection group of the micro-pore model, the part of Fig. 9(a) outside the sky blue) to find deleted redundant isolated pores. Finally, the grid is divided, and the grid after division is shown as shown in Fig. 9(b). After grid partition, CFX-Pre software is used to configure the boundary conditions and solvers of the generated meshes. The simulation is based on unsteady Navier-Stokes equation. The incompressible N-S equation can be used to simulate fluid flow in the micro pores of coal [34]. Navier-Stokes equation in vector form:

$\rho\left[\frac{\partial v}{\partial t}+(v \cdot \nabla) v\right]=\rho f-\nabla p+\mu \nabla^{2} v$

where the left side of the equal sign describes inertia. $\rho$ is the fluid density, $v$ is the fluid velocity, $p$ is the fluid pressure, $\mu$ is the viscosity, $\rho f$ represents body forces, $\nabla p$ is the pressure gradient, $\mu \nabla^{2} v$ represents viscosity forces.

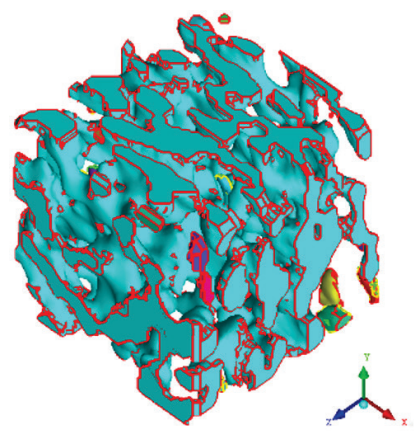

(a) Splitting isolated pores

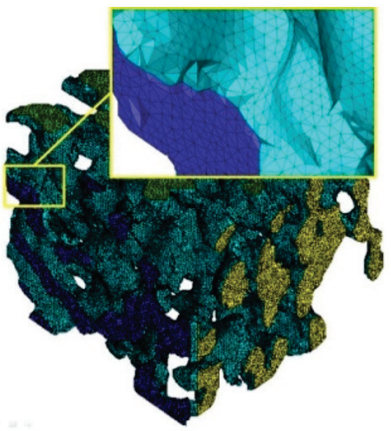

(b) meshing
Figure 9 Meshing of micro pore model of coal based on the ICEM

The k-epsilon turbulence model is used and the property of fluid material is set as water at normal temperature $(298 \mathrm{~K})$. The acceleration of gravity is set to $9,8 \mathrm{~m} / \mathrm{s}^{2}$ in a vertically downward direction which is the negative direction of $z$-axis. It should be noted that the negative direction of $z$-axis is the original gravity direction of coal sample. The $-X,+X,-Y,+Y,-Z$ and $+Z$ are configured respectively as seepage inlets and the remaining five planes are configured as outlets. Pressures at the inlet and outlets are respectively configured as 3,1 $\mathrm{MPa}$ and 0,1 $\mathrm{MPa}$. The simulation of seepage during water injection with one inlet and five outlets is then performed. Fig. 10 shows an example of setting boundary conditions with $-X$ as seepage inlet.
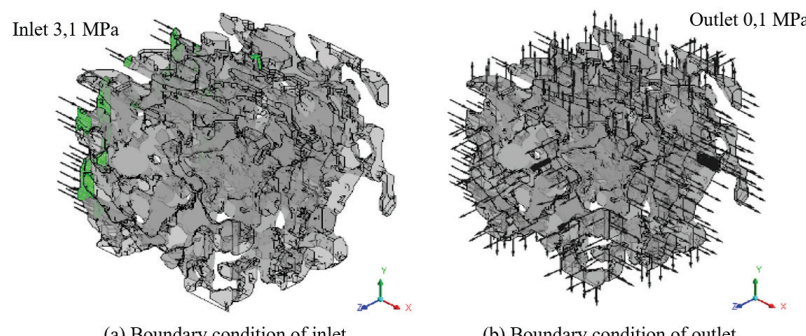

Figure 10 Setting of boundary conditions

For simplified analysis, the following assumptions are employed: water only flows in the pores and does not permeate into the solid coal material; the fluid is incompressible and has a constant temperature of $298 \mathrm{~K}$ during the flowing process; the flow is continuous and never interrupted during the flowing process; the flow is influenced only by gravity and pressure. 


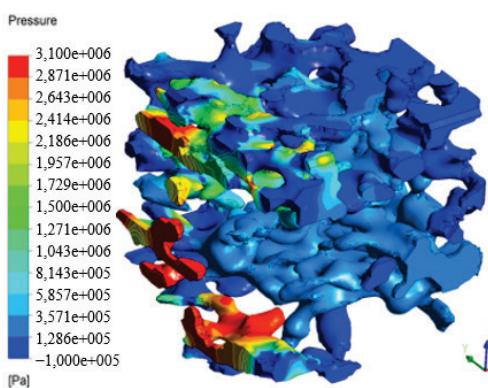

(a) $-X$

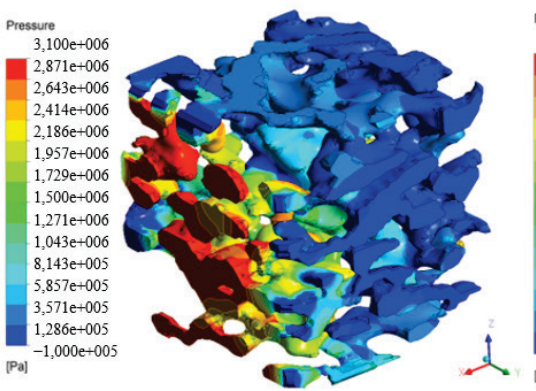

(d) $+X$

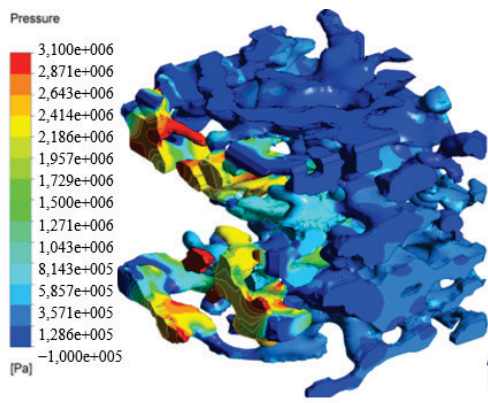

(b) $-Y$

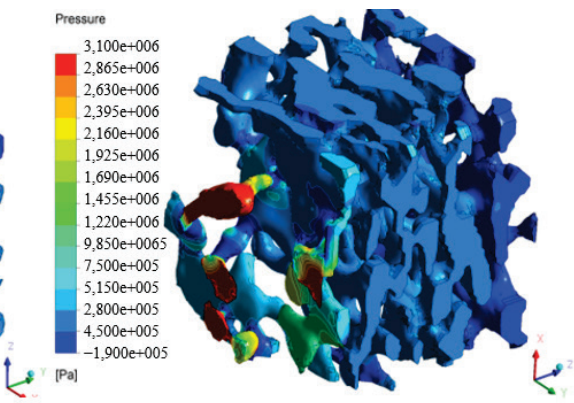

(c) $-Z$

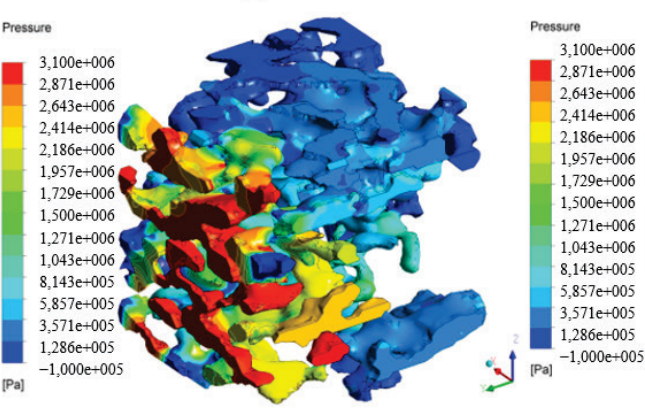

(e) $+Y$

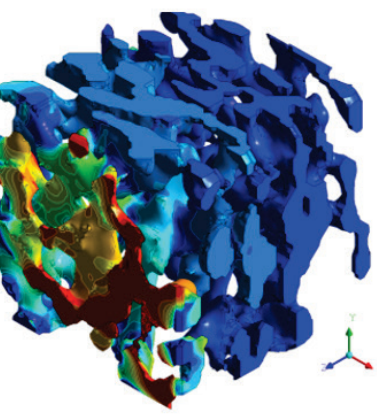

$(\mathrm{f})+Z$

Figure 11 Pressure field distributions in different scenarios of seepage inlet

\subsection{Results and Discussion}

Three-dimensional pressure distribution of the coal pores is shown in Fig. 11. Fig. 12 shows the 3D seepage streamline and velocity distribution of micro pores of coal, and Fig. 13 display the distributions of mass flow rate on different exit faces under different inlet conditions (Take $X$ as an example), where the red color of the scale bar indicates high pressure / velocity and the blue color refers to low pressure/velocity. The visualized numerical simulation diagrams give a clear view of the 3D distribution and variation of water pressure, water velocity and mas flow rate in the micro pores, as well as the flowing features of water in micro pores.

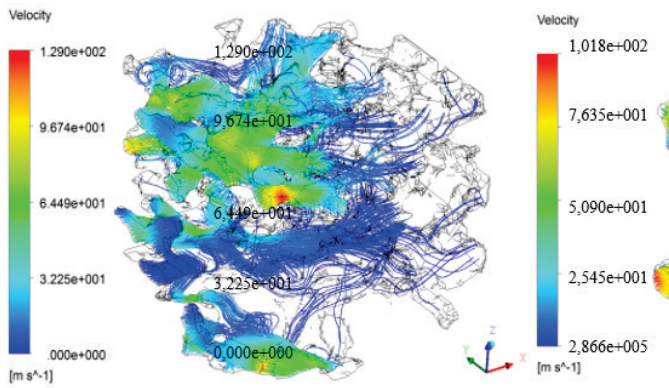

(a) $-X$
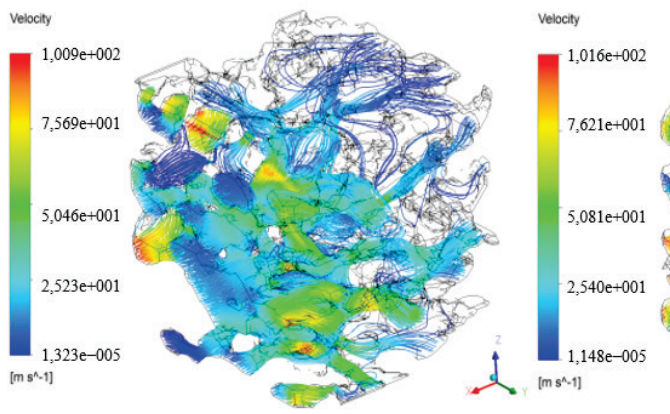

(d) $+X$

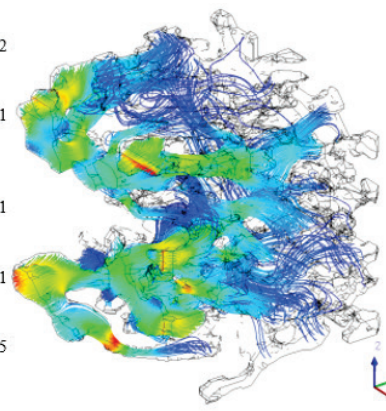

(b) $-Y$

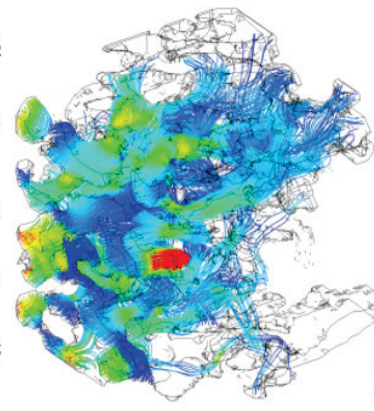

(e) $+Y$
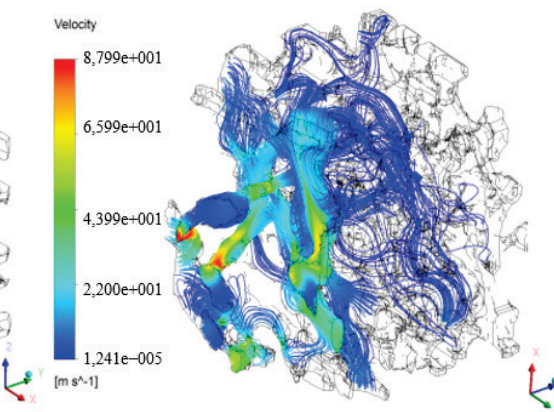

(c) $-Z$
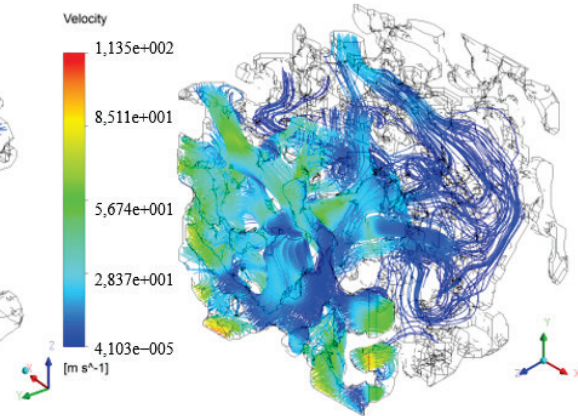

$(f)+Z$

Figure 12 Water flow streamline and velocity distribution in different scenarios of seepage inlet

\subsubsection{Analysis of the Simulated Seepage Pressure Fields During Water Injection}

According to Fig. 12, along different directions the shapes, sizes, connectivity and permeability of pore channels are different. This means that the 3D distribution and variation of pore pressure are different when different planes are selected as seepage inlets. The major difference lies in the pressure gradient. There is large pressure gradient in vertical direction due to gravity, and the 
pressure gradient in the other four directions is small. The 3D distribution of water pressure at different planes selected as seepage inlets still presents certain rule: the water pressure gradually decreases along the direction of water seepage and reaches the highest at the pore-pipes with good connectivity near the inlet; the water pressure rises to some extent after a large drop but generally decreases when water flow passes through shallow pores; the water pressure linearly drops when water flow passes through wider pores. Wang et al. established the coal's finite element model by means of CT-based 3D reconstruction and reverse engineering, and simulated the seepage behaviors of gas in the coal along $X, Y$ and $Z$ directions, which can describe the spatial distributions of pressure field and velocity field in gas seepage process visually and directly

\subsubsection{Analysis on the Pressure Field of Seepage during Water Injection}

According to Fig. 12, along different directions the water pressure distribution, pore-pipe structure and permeability are different, so the 3D water flow and velocity distribution and change inside the pores are different when different planes are selected as seepage inlets. The major difference lies in the 3D flowing features. Due to the influence of gravity and the development of pore structure, when $-Z$ plane is set as the inlet, the maximum velocity of $87,99 \mathrm{~m} / \mathrm{s}$ is smaller than those of the other five seepage planes. However, there is evident water flow in the directions of $x$-axis and $y$-axis and the flow is mainly horizontal. Even so, the 3D flow of water and 3D distribution of velocity in different scenarios of seepage inlet still exhibit consistent rule: though all the pores of the biggest pore connection group are connected, there is still a large number of pores without any water flow. The flow paths that have large pore diameter, short path and small distance to the outlet, are selected with priority during the seepage process. From the perspective of a single pore pipe, water velocity gradually decreases as long as its flow direction is along the center-to-wall direction of the pore. From the perspective of the whole micro-pore structure, the largest velocity exists at shallow pores, which have sufficient water seepage and maintain short distance to the inlet and large pressure drop.

\subsubsection{Analysis on the Distribution Pattern of Mass Flow Rate at Different Outlets with Only One Inlet}

The fluid's mass flow rate was poorly investigated in the previous studies. Zhou et al. through statistics of the mass flow rate averaged at different sections of the water in the unidirectional flow of coal in the microstructure, the mass flow field variation rule is analyzed. It is found that the mean mass flow rate in the $Z$ direction is largely affected by gravity. By contrast, this study focuses on the fluid's mass flow rate in addition to seepage pressure field and seepage velocity field after water injection. A comprehensive analysis of the fluid's mass flow rates at different exits under different inlet conditions can help to gain in-depth knowledge of fluid's seepage rules in the coal from a micro perspective.
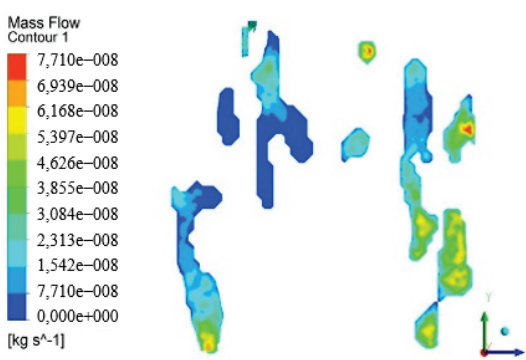

(a) $-X(\ln )$

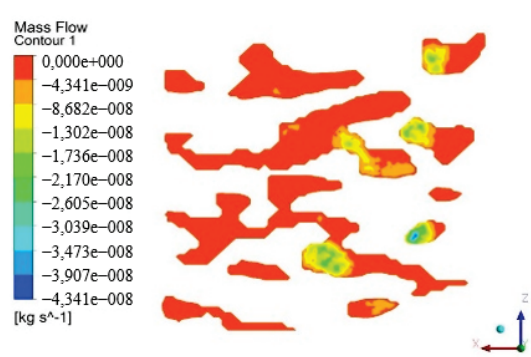

(d) $+Y$

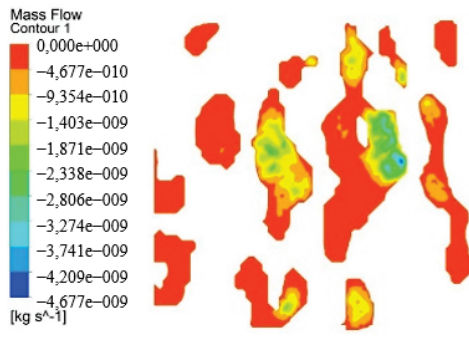

(b) $+X$

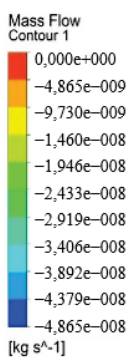
$\left[\mathrm{kg} \mathrm{s}^{\mathrm{n}-1,-1]}\right.$

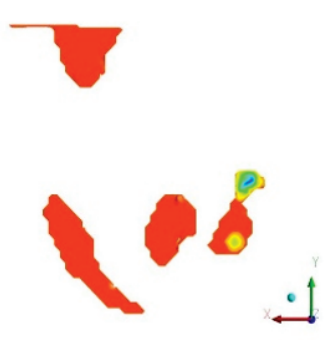

(e) $-Z$
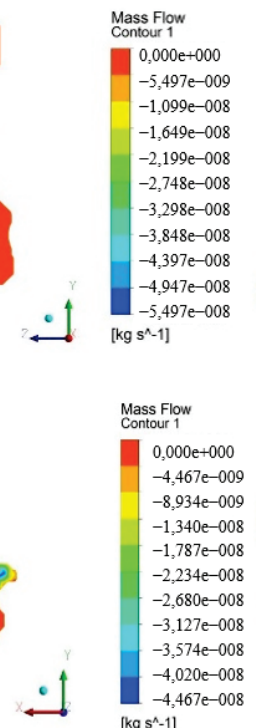

$\left[\mathrm{kg} \mathrm{s}^{\mathrm{s}-1]}\right.$

Figure 13 Distribution of mass flow rate of $-\mathrm{X}$ at inlet

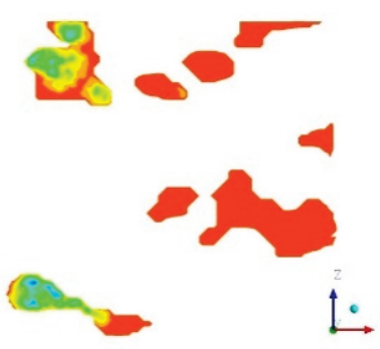

(c) $-Y$

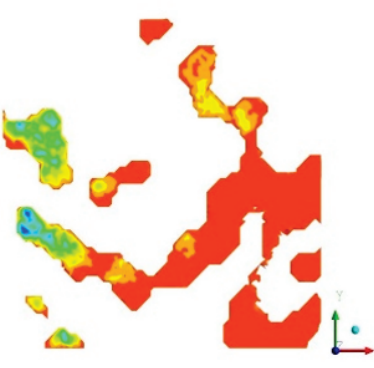

$(f)+Z$
The plus and minus scale intervals on the mass flow rate scale indicate the mass flow rate of fluids from different sources: plus for fluids at the inlet and minus for fluids at the outlet. In this paper, the values of mass flow rate are described without a plus or a minus. According to Fig. 13, the maximum mass flow rate at each outlet is lower than that at the inlet when water is injected from different inlets. For example, when the $-X$ plane is selected as the inlet, the maximum mass flow rate is $7,71 \times 10^{-8} \mathrm{~kg} / \mathrm{s}$ while the maximum mass flow rates at the outlets on $+X,-Y,+Y$, $-Z$, and $+Z$ planes are lower. They are respectively $4,677 \times$ $10^{-9} \mathrm{~kg} / \mathrm{s} ; 5,497 \times 10^{-8} \mathrm{~kg} / \mathrm{s} ; 4,341 \times 10^{-8} \mathrm{~kg} / \mathrm{s} ; 4,865 \times 10^{-8}$ $\mathrm{kg} / \mathrm{s}$ and $4,467 \times 10^{-8} \mathrm{~kg} / \mathrm{s}$. The same change pattern of mass flow rate is observed in the analysis of other models. This pattern is caused by the fact that fluids injected from one inlet are diverted to five outlets. 
Table 2 Mass flow rate distribution of each outlet in different scenarios of seepage inlet

\begin{tabular}{|c|c|c|c|c|}
\hline Seepage inlet & Mass flow rate of inlet $/ \mathrm{kgs}^{-1}$ & Seepage outlet & Mass flow rate of outlet $/ \mathrm{kgs}^{-1}$ & Percentage of gross flowrate \\
\hline \multirow{5}{*}{$-X$} & \multirow{5}{*}{$2.27 \mathrm{E}-05$} & $+X$ & $8.28 \mathrm{E}-07$ & $3,64 \%$ \\
\hline & & $-Y$ & $7,14 \mathrm{E}-06$ & $31,41 \%$ \\
\hline & & $+Y$ & $4,57 \mathrm{E}-06$ & $20,12 \%$ \\
\hline & & $-Z$ & $9,68 \mathrm{E}-07$ & $4,26 \%$ \\
\hline & & $+Z$ & $9,25 \mathrm{E}-06$ & $40,70 \%$ \\
\hline \multirow{5}{*}{$+X$} & \multirow{5}{*}{$2,58 \mathrm{E}-05$} & $-X$ & $1,74 \mathrm{E}-06$ & $6,72 \%$ \\
\hline & & $-Y$ & $6,79 \mathrm{E}-06$ & $26,28 \%$ \\
\hline & & $+Y$ & $1,12 \mathrm{E}-05$ & $43,37 \%$ \\
\hline & & $-Z$ & $1,29 \mathrm{E}-06$ & $5,00 \%$ \\
\hline & & $+Z$ & $4,85 \mathrm{E}-06$ & $18,75 \%$ \\
\hline \multirow{5}{*}{$-Y$} & \multirow{5}{*}{$2,32 \mathrm{E}-05$} & $-X$ & $7,97 \mathrm{E}-06$ & $34,30 \%$ \\
\hline & & $+X$ & $7,58 \mathrm{E}-06$ & $32,58 \%$ \\
\hline & & $+Y$ & $1,23 \mathrm{E}-06$ & $5,29 \%$ \\
\hline & & $-Z$ & $1,41 \mathrm{E}-06$ & $6,07 \%$ \\
\hline & & $+Z$ & $5,08 \mathrm{E}-06$ & $21,84 \%$ \\
\hline \multirow{5}{*}{$+Y$} & \multirow{5}{*}{$2,30 \mathrm{E}-05$} & $-X$ & $3,19 \mathrm{E}-06$ & $14,17 \%$ \\
\hline & & $+X$ & $1,19 \mathrm{E}-05$ & $51,49 \%$ \\
\hline & & $-Y$ & $2,52 \mathrm{E}-06$ & $10,96 \%$ \\
\hline & & $-Z$ & $2,32 \mathrm{E}-06$ & $10,10 \%$ \\
\hline & & $+Z$ & $3,34 \mathrm{E}-06$ & $14,51 \%$ \\
\hline \multirow{5}{*}{$-Z$} & \multirow{5}{*}{$5,36 \mathrm{E}-06$} & $-X$ & $1,38 \mathrm{E}-06$ & $25,77 \%$ \\
\hline & & $+X$ & $1,26 \mathrm{E}-06$ & $23,42 \%$ \\
\hline & & $-Y$ & $1,17 \mathrm{E}-06$ & $21,87 \%$ \\
\hline & & $+Y$ & $1,57 \mathrm{E}-06$ & $29,23 \%$ \\
\hline & & $+Z$ & $0,00 \mathrm{E}+00$ & $0,00 \%$ \\
\hline \multirow{5}{*}{$+Z$} & \multirow{5}{*}{$2,16 \mathrm{E}-05$} & $-X$ & $8,00 \mathrm{E}-06$ & $36,95 \%$ \\
\hline & & $+X$ & $4,36 \mathrm{E}-06$ & $20,14 \%$ \\
\hline & & $-Y$ & $6,06 \mathrm{E}-06$ & $27,98 \%$ \\
\hline & & $+Y$ & $3,26 \mathrm{E}-06$ & $15,04 \%$ \\
\hline & & $-Z$ & $0,00 \mathrm{E}+00$ & $0,00 \%$ \\
\hline
\end{tabular}

\subsubsection{Analysis of the Mass Flow Rate and Velocity Field}

Although some scholars conducted numerical simulations on the seepage behaviors of other fluids in the coal from a micro perspective, they did not delve into the relations between mass flow rate at both exit and inlet and the velocity field for revealing the development direction of pores in the coal from the perspective of mass flow rate. For a deeper quantitative study on the rules of seepage in the microstructure of coal, the mass flow rate and velocity of each outlet in different scenarios of seepage inlet are obtained via CFD-Post software, as shown in Tab. 2 and Tab. 3. Fig. 19 shows the pie charts of the percentage of mass flow rate of five outlets and mass flow rate of the inlet in different scenarios.

According to Tab. 2 and Fig. 14, when fluids enter the pores of coal from the inlets of different orientations, the
3D variations in the pore structure and development direction cause the majority of the fluids to flow through the plane with the best connectivity. It can be found in the mass flow rate distribution diagram of each outlet with different inlets that there is always a seepage outlet that has the largest flow rate among all the outlets.

Therefore, the direction from the inlet to the optimal seepage plane is called the optimal seepage direction and expressed as $+X \rightarrow+Y$. After an overall analysis, it can be found that the optimal seepage directions include $-X \rightarrow+Z$, $-Y \rightarrow-X,-Z \rightarrow+Y,+X \rightarrow+Y,+Y \rightarrow+X$ and $+Z \rightarrow-X$. Among the six combinations, there is one optimal seepage combination, i.e. $+Y \rightarrow+X$. When the inflow is normal to $+Y$ plane, up to $51 \%$ of it exits from $+X$ plane, which is higher than the other five combinations.

Table 3 Seepage velocity distribution of each outlet in different scenarios of seepage inlet

\begin{tabular}{|c|c|c|c|c|c|c|c|c|c|}
\hline $\begin{array}{c}\text { Seepage } \\
\text { inlet }\end{array}$ & $\begin{array}{l}\text { Inlet velocity / } \\
\mathrm{m} / \mathrm{s}\end{array}$ & $\begin{array}{c}\text { Seepage } \\
\text { outlet }\end{array}$ & $\begin{array}{l}\text { Outlet velocity } \\
/ \mathrm{m} / \mathrm{s}\end{array}$ & $\begin{array}{l}\text { Average outlet } \\
\text { velocity } / \mathrm{m} / \mathrm{s}\end{array}$ & $\begin{array}{c}\text { Seepage } \\
\text { inlet }\end{array}$ & $\begin{array}{l}\text { Inlet velocity / } \\
\mathrm{m} / \mathrm{s}\end{array}$ & $\begin{array}{c}\text { Seepage } \\
\text { outlet }\end{array}$ & $\begin{array}{l}\text { Outlet velocity } \\
/ \mathrm{m} / \mathrm{s}\end{array}$ & $\begin{array}{l}\text { Average outlet } \\
\text { velocity } / \mathrm{m} / \mathrm{s}\end{array}$ \\
\hline \multirow{5}{*}{$-X$} & \multirow{5}{*}{37,69} & $+X$ & 1,11 & \multirow{5}{*}{9,23} & \multirow{5}{*}{$+X$} & \multirow{5}{*}{24,54} & $-X$ & 3,63 & \multirow{5}{*}{11,004} \\
\hline & & $-Y$ & 16,06 & & & & $-Y$ & 17,29 & \\
\hline & & $+Y$ & 7,36 & & & & $+Y$ & 13,67 & \\
\hline & & $-Z$ & 4,88 & & & & $-Z$ & 10,95 & \\
\hline & & $+Z$ & 16,74 & & & & $+Z$ & 9,48 & \\
\hline \multirow{5}{*}{$-Y$} & \multirow{5}{*}{42,27} & $-X$ & 19,70 & \multirow{5}{*}{9,7} & \multirow{5}{*}{$+Y$} & \multirow{5}{*}{23,00} & $-X$ & 12,41 & \multirow{5}{*}{10,072} \\
\hline & & $+X$ & 9,00 & & & & $+X$ & 14,41 & \\
\hline & & $+Y$ & 2,02 & & & & $-Y$ & 5,09 & \\
\hline & & $-Z$ & 9,06 & & & & $-Z$ & 11,58 & \\
\hline & & $+Z$ & 8,72 & & & & $+Z$ & 6,87 & \\
\hline \multirow{5}{*}{$-Z$} & \multirow{5}{*}{23,77} & $-X$ & 14,84 & \multirow{5}{*}{7,72} & \multirow{5}{*}{$+Z$} & \multirow{5}{*}{16,58} & $-X$ & 3,56 & \multirow{5}{*}{2,146} \\
\hline & & $+X$ & 5,94 & & & & $+X$ & 1,91 & \\
\hline & & $-Y$ & 13,62 & & & & $-Y$ & 2,56 & \\
\hline & & $+Y$ & 4,05 & & & & $+Y$ & 2,10 & \\
\hline & & $+Z$ & 0,15 & & & & $-Z$ & 0,60 & \\
\hline
\end{tabular}




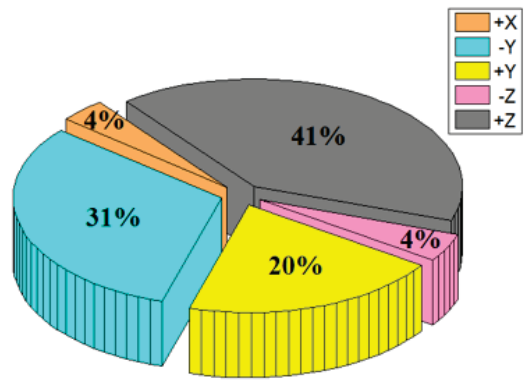

(a) $-X$

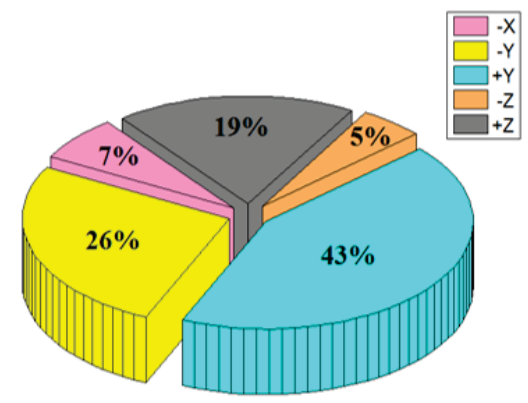

(d) $+X$

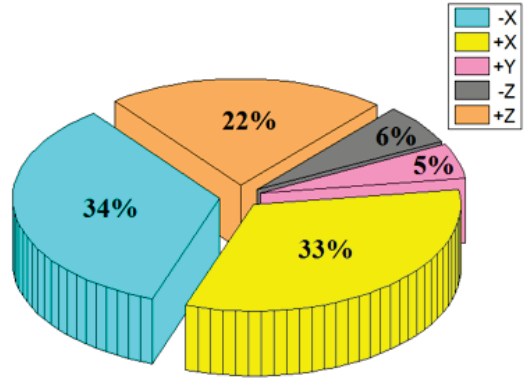

(b) $-Y$

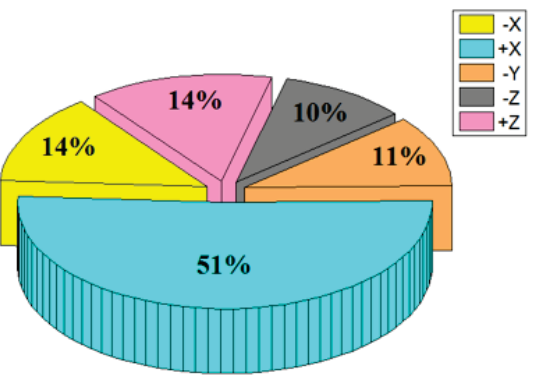

(e) $+Y$

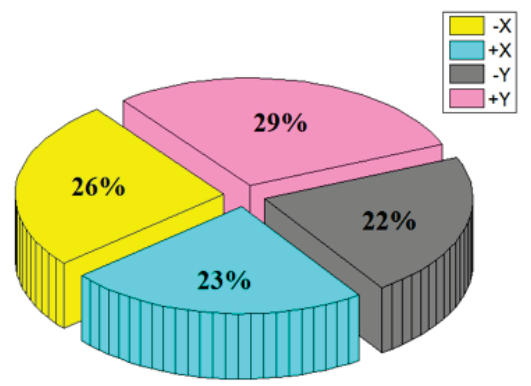

(c) - Z

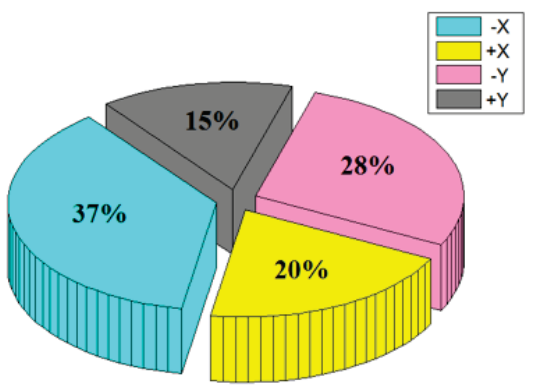

(f) $+Z$

Figure 14 Chart of percentage of mass flow rate at each outlet in different scenarios of seepage inlet

According to Tab. 3, when different planes are selected as seepage inlets, the velocity of seepage inlet and outlet varies within a wide range, $16,58-42,27 \mathrm{~m} / \mathrm{s}$ at the inlet and $2,146-11,004 \mathrm{~m} / \mathrm{s}$ at the outlet. This is due to the influence of pore structure, pore development direction and gravity, and it reflects the complicated nature of distribution.

(1) It can be found in Tab. 2 that the flow velocity at each seepage outlet is positively correlated with the seepage mass flow rate at the outlet when different planes are selected as seepage inlets.

(2) When $-X,-Y,+X$ and $+Y$ planes are selected as seepage inlets, the velocity at $-X$ or $-Y$ inlets is bigger than that at $+X$ or $+Y$ inlets. This is because compared with $+X$ and $+Y$ planes, there are very few pores near the $-X$ and $Y$ planes and the pores are not well developed. In brief, the velocity of seepage inlets is negatively correlated with the amounts of pores near seepage inlets.

(3) Due to the fact that seepage in $Z$ direction is more influenced than the others, a separate study on $+Z$ and $-Z$ planes is conducted. Due to the influence of gravity, there should have been larger inlet velocity when $+Z$ plane is selected as the seepage inlet. However, the opposite conclusion is found in the results. This is because the amount of pores near the $+Z$ plane is bigger than that around $-Z$ plane, which shows that the influence of the amount of pores on seepage velocity is more significant than gravity.

\section{CONCLUSIONS}

In the present study a model of micro-pore structure of coal was constructed through image segmentation, and a numerical simulation of seepage during water injection with one inlet and five outlets in micro-pore structure of coal was performed in combination with CFX finite element software. The result shows the following: water pressure gradually decreases along the direction of water seepage and reaches its maximum at the pore-pipes with good connectivity near the inlet; water pressure rises to some extent after a large drop but generally decreases when water flow passes through shallow pores. Due to the fact that fluids injected from one inlet are diverted to five outlets, the maximum mass flow rate at each outlet is lower than that at the inlet when water is injected from different inlets, and if the maximum mass flow rate of an outlet is the smallest of the six models, the plane of this outlet is on the opposite side of the inlet plane. Due to the difference between the structure and development direction of pores in the three dimensions, there is an optimal seepage outlet that is most appropriately corresponding to each seepage inlet. When different planes are selected as seepage inlets, the velocity of each seepage outlet is positively correlated with the seepage mass flow rate at the outlet. The velocity at seepage inlets is negatively correlated with the amounts of pores near seepage inlets, and the amount/structure of pores has greater influence on seepage velocity than gravity.

\section{Acknowledgements}

This work was financially supported by the National Key Research and Development Program of China (Grant no. 2017YFC0805202), the National Natural Science Foundation of China (Grant no. 51774198, 51474139), the Outstanding Youth Fund Project of Provincial Universities in Shandong Province (Grant no. ZR2017JL026), the Taishan Scholar Talent Team Support Plan for Advantaged \& Unique Discipline Areas, the Qingdao City Science and Technology Project (Grant no. 16-6-2-52-nsh), the China Postdoctoral Science Foundation Funded Special Project (Grant no. 2016T90642), the China postdoctoral Science Foundation Funded Project (Grant no. 2015M570602), the Qingdao Postdoctoral Applied Research Project (Grant no. 2015194). 


\section{REFERENCES}

[1] Cheng, W., Hu, X., Xie, J., \& Zhao, Y. (2017). An intelligent gel designed to control the spontaneous combustion of coal: Fire prevention and extinguishing properties. Fuel, 210(Supplement C), 826-835. https://doi.org/10.1016/j.fuel.2017.09.007

[2] Li, X. \& Yin, G. (2011). Contrast test of microscopic characteristics and seepage properties of different coals. Chinese Journal of Rock Mechanics \& Engineering, 30(3), 500508.

[3] Rong, H. \& Hai, B. (2014). Pore structure characteristics of the relative water-resisting layer on the top of the Ordovician in Longgu coal mine. International Journal of Mining Science and Technology, 24(5), 657-661. https://doi.org/10.1016/j.ijmst.2014.04.001

[4] Nie, W., Wei, W., Ma, X., Liu, Y., Peng, H., \& Liu, Q. (2017). The effects of ventilation parameters on the migration behaviors of head-on dusts in the heading face. Tunnelling \& Underground Space Technology, 70, 400-408. https://doi.org/10.1016/j.tust.2017.09.017

[5] Baker, D. R., Mancini, L., Polacci, M., Higgins, M. D., Gualda, G. A. R., Hill, R. J., et al. (2012). An introduction to the application of x-ray microtomography to the threedimensional study of igneous rocks. Lithos, 148(9), 262-276. https://doi.org/10.1016/j.lithos.2012.06.008

[6] Zhang, Q., Zhou, G., Qian, X. M., Yuan, M. Q., Sun, Y. L., \& Wang, D. (2018). Diffuse pollution characteristics of respirable dust in fully-mechanized mining face under various velocities based on CFD investigation. Journal of Cleaner Production, 184, 239-250. https://doi.org/10.1016/j.jclepro.2018.02.230

[7] Zhou, G., Zhang, Q., Bai, R. N., Fan, T., \& Wang, G. (2017). The diffusion behavior law of respirable dust at fully mechanized caving face in coal mine: CFD numerical simulation and engineering application. Process Safety and Environmental Protection, 106, 117-128. https://doi.org/10.1016/j.psep.2016.12.005

[8] Zhou, G., Ma, Y. L., Fan, T., \& Wang, G. (2018). Preparation and characteristics of a multifunctional dust suppressant with agglomeration and wettability performance used in coal mine. Chemical Engineering Research and Design, 132, 729-742. https://doi.org/10.1016/j.cherd.2018.02.021

[9] Fan, T., Zhou, G., \& Wang, J. Y. (2018). Preparation and characterization of a wetting-agglomeration-based hybrid coal dust suppressant. Process Safety and Environmental Protection, 113, 282-291. https://doi.org/10.1016/j.psep.2017.10.023

[10] Hu, Z., Hu, X., Cheng, W., \& Lu, W. (2018). Influence of synthetic conditions on the performance of melaminephenol-formaldehyde resin microcapsules. High Performance Polymers. https://doi.org/10.1177/0954008318758489

[11] Nie, B., He, X., Li, X., Chen, W., \& Hu, S. (2014). Mesostructures evolution rules of coal fracture with the computerized tomography scanning method. Engineering Failure Analysis, 41(5), 81-88. https://doi.org/10.1016/j.engfailanal.2013.10.007

[12] Wang, J. Y., Zhou, G., Wei X., \& Wang, S. C. (2019). Experimental characterization of multi-nozzle atomization interference for dust reduction between hydraulic supports at a fully mechanized coal mining face. Environmental Science and Pollution Research, 26(10), 10023-10036. https://doi.org/10.1007/s11356-019-04413-w

[13] Cheng, W., Liu, Z., Yang, H., \& Wang, W. (2017). Non-linear seepage characteristics and influential factors of water injection in gassy seams. Experimental Thermal \& Fluid Science, 91, 41-53. https://doi.org/10.1016/j.expthermflusci.2017.10.002

[14] Li, S. L., Zhou, G., Wang, Y. Y., Jing B., \& Qu, Y. L.(2019).
Synthesis and characteristics of fire extinguishing gel with high water absorption for coal mines. Process Safety and Environmental Protection, 125: 207-218. https://doi.org/10.1016/j.psep.2019.03.022

[15] Song, X. X., Tang, Y. G., Li, W., Feng, Z. C., Kang, Z. Q., \& Li, Y. J., et al. (2013). Advanced characterization of seepage pores in deformed-coals based on micro-ct. Journal of China Coal Society, 38(3), 435-440.

[16] Ma, Y. L., Zhou, G., Ding J. F., Li, S. L., \& Wang G. (2018). Preparation and characterization of an agglomerationcementing agent for dust suppression in open pit coal mining. Cellulose, 25, 4011-4029. https://doi.org/10.1007/s10570-018-1826-z

[17] Zhou, G., Fan, T., Xu, M., Qiu, H., Wang, J., \& Qiu, L. (2018). The development and characterization of a novel coagulant for dust suppression in open-cast coal mines. Adsorption Science \& Technology, 36(1-2), 608-624. https://doi.org/10.1177/0263617417711025

[18] Ma, Y. L., Zhou, G., Li, S. L., \& Ding J. F. (2018). Synthesis and properties of a conglomeration-wetting spray agent for dust suppression. Industrial \& Engineering Chemistry Research, 57(42), 13940-13951. https://doi.org/10.1021/acs.iecr.8b03241

[19] Zhou, G., Feng, B., Yin, W. J., \& Wang, J. Y. (2018). Numerical simulations on airflow-dust diffusion rules with the use of coal cutter dust removal fans and related engineering applications in a fully-mechanized coal mining face. Powder Technology, 339, 354-367. https://doi.org/10.1016/.j.powtec.2018.07.078

[20] Li, W., Yao, H. F., Liu, H. F., Kang, Z. Q., Song, X. X., \& Feng, Z. C. (2014). Advanced characterization of threedimensional pores in coals with different coal-body structure by micro-CT. Journal of China Coal Society, 39(6), 11271132(6).

[21] Mostaghimi, P., Blunt, M. J., \& Bijeljic, B. (2013). Computations of absolute permeability on micro-CT images. Mathematical Geosciences, 45(1), 103-125. https://doi.org/10.1007/s11004-012-9431-4

[22] Mayo, S., Josh, M., Nesterets, Y., Esteban, L., Pervukhina, M., Clennell, M. B., et al. (2015). Quantitative microporosity characterization using synchrotron micro-ct and xenon k-edge subtraction in sandstones, carbonates, shales and coal. Fuel, 154, 167-173. https://doi.org/10.1016/j.fuel.2015.03.046

[23] Simons, F. J., Verhelst, F., \& Swennen, R. (1997). Quantitative characterization of coal by means of microfocal $\mathrm{X}$-ray computed microtomography (CMT) and color image analysis (CIA). International Journal of Coal Geology, 34(12), 69-88. https://doi.org/10.1016/S0166-5162(97)00011-6

[24] Mazumder, S., Wolf, K. H. A. A., Elewaut, K., \& Ephraim, R. (2006). Application of x-ray computed tomography for analyzing cleat spacing and cleat aperture in coal samples. International Journal of Coal Geology, 68(3-4), 205-222. https://doi.org/10.1016/j.coal.2006.02.005

[25] Wang, H., Nie, W., Cheng, W., Liu, Q., \& Jin, H. (2018). Effects of air volume ratio parameters on air curtain dust suppression in a rock tunnel's fully-mechanized working face. Advanced Powder Technology, 29(2), 230-244. https://doi.org/10.1016/j.apt.2017.11.007

[26] Golab, A., Ward, C. R., Permana, A., Lennox, P., \& Botha, P. (2013). High-resolution three-dimensional imaging of coal using microfocus $\mathrm{x}$-ray computed tomography, with special reference to modes of mineral occurrence. International Journal of Coal Geology, 113(7), 97-108. https://doi.org/10.1016/..coal.2012.04.011

[27] Geet, M. V., Swennen, R., \& David, P. (2001). Quantitative coal characterisation by means of microfocus X-ray computer tomography, colour image analysis and back-scattered scanning electron microscopy. International Journal of Coal Geology, 46(1), 11-25. 
https://doi.org/10.1016/S0166-5162(01)00006-4

[28] Mathews, J. P. \& Pone, J. (2011). High-resolution x-ray computed tomography observations of the thermal drying of lump-sized subbituminous coal. Fuel Processing Technology, 92(1), 58-64. https://doi.org/10.1016/j.fuproc.2010.08.020

[29] Karacan, C. O. \& Okandan, E. (2001). Adsorption and gas transport in coal microstructure: investigation and evaluation by quantitative X-ray CT imaging. Fuel, 80(4), 509-520. https://doi.org/10.1016/S0016-2361(00)00112-5

[30] Zhou, G., Zhang, Q., Bai, R., \& Ni, G. (2016). Characterization of coal micro-pore structure and simulation on the seepage rules of low-pressure water based on CT scanning data. Minerals, 6(3), 78 . https://doi.org/10.3390/min6030078

[31] Zhou, G., Qiu, L., Zhang, W. Z., \& Xue, J. (2018). Simulation Analysis on Water's Micro Seepage Laws under Different Pressure Gradients Using Computed Tomography Method. Advances in Civil Engineering, 26 pages. https://doi.org/10.1155/2018/3401341

[32] Dierick, M., Loo, D. V., Masschaele, B., Bulcke, J. V. D., Acker, J. V., Cnudde, V., et al. (2014). Recent micro-ct scanner developments at UGCT. Nuclear Instruments \& Methods in Physics Research, 324, 35-40. https://doi.org/10.1016/j.nimb.2013.10.051

[33] Jiang, Y. \& Liang, B. (2010). Numerical Simulation of Coal Deformation and Gas Seepage after Cutting in LowPermeability Coal Seams. International Symposium on Multi-field Coupling Theory of Rock and Soil (pp. 616-620).

[34]Bird, M. B., Butler, S. L., Hawkes, C. D., \& Kotzer, T. (2014). Numerical modeling of fluid and electrical currents through geometries based on synchrotron X-ray tomographic images of reservoir rocks using Avizo and COMSOL. Computers \& Geosciences, 73(C), 6-16.

https://doi.org/10.1016/j.cageo.2014.08.009

\section{Contact information:}

\section{Gang ZHOU, Prof. PhD}

(Corresponding author)

College of Mining and Safety Engineering,

Shandong University of Science and Technology,

579 Qianwangang Road, Economic \& Technical Development Zone, Qingdao

266590, China,

State Key Laboratory of Mining Disaster Prevention and Control Co-founded by

Shandong Province and the Ministry of Science and Technology,

Shandong University of Science and Technology,

579 Qianwangang Road, Economic \& Technical Development Zone, Qingdao

266590, China

E-mail: zhougang@sdust.edu.cn

Lei QIU, Undergraduate for Master

College of Mining and Safety Engineering,

Shandong University of Science and Technology,

579 Qianwangang Road, Economic \& Technical Development Zone, Qingdao

266590, China

Wen-zheng ZHANG, Undergraduate for Master

College of Mining and Safety Engineering,

Shandong University of Science and Technology,

579 Qianwangang Road, Economic \& Technical Development Zone, Qingdao

266590, China

\section{Jiao XUE, Experimenter}

State Key Laboratory of Mining Disaster Prevention and Control Co-founded by

Shandong Province and the Ministry of Science and Technology,

Shandong University of Science and Technology,

579 Qianwangang Road, Economic \& Technical Development Zone, Qingdao

266590, China

Ming-guang ZHANG, Lecturer

College of Mining and Safety Engineering,

Shandong University of Science and Technology,

579 Qianwangang Road, Economic \& Technical Development Zone, Qingdao 266590, China 